\title{
Human Rights, Claimability, and the Uses of Abstraction
}

\author{
ADAM ETINSON \\ The Graduate Center, City University of New York
}

\begin{abstract}
This article addresses the so-called 'claimability objection' to human rights. Focusing specifically on the work of Onora O'Neill, the article challenges two important aspects of her version of this objection. First: its narrowness. O'Neill understands the claimability of a right to depend on the identification of its dutybearers. But there is good reason to think that the claimability of a right depends on more than just that, which makes abstract (and not welfare) rights the most natural target of her objection (Section II). After examining whether we might address this reformulated version of O'Neill's objection by appealing to the specificity afforded to human rights in international, regional, and domestic law (in Section III), the article challenges a second important feature of that objection by raising doubts about whether claimability is a necessary feature of rights at all (Section IV). Finally, the article reflects more generally on the role of abstraction in the theory and practice of human rights (Section V). In sum, by allaying claimability-based concerns about abstract rights, and by illustrating some of the positive functions of abstraction in rights discourse, the article hopes to show that abstract rights are not only theoretically coherent but also useful and important.
\end{abstract}

Human rights culture has often been accused of a certain imbalance. For instance, it is often said that the practitioners of human rights (i.e. lawyers, politicians, judges, legislators, intellectual advocates, activists, etc.) are too quick to proclaim the existence of rights and too slow to define or allocate attendant duties. ${ }^{1}$ It is not difficult to locate the grounds of such complaints. In a manner typical of most prominent declarations, the 1948 Universal Declaration of Human Rights (UDHR) states that members of the United Nations should take 'progressive measures, national and international, to secure [the] universal and effective recognition and observance, ${ }^{2}$ of the human rights it proclaims, e.g. rights to freedom from torture, oppression, arbitrary arrest, poverty, unemployment, starvation, and exile. But the UDHR rarely goes into any serious detail about what member states are concretely required to do in order to secure such rights. And while legally binding human rights treaties and covenants are generally less reticent in this respect, ${ }^{3}$ they similarly leave a wide range of deontic questions unanswered. For one, like prominent

\footnotetext{
${ }^{1}$ Throughout this article, I will use the terms 'duty' and 'obligation' interchangeably.

${ }^{2}$ UDHR, Preamble.

${ }^{3}$ For instance, the International Covenant on Economic, Social and Cultural Rights (ICESCR) is more specific about the human right to work, claiming that it can only be fully realized by steps that include, among other measures, 'technical and vocational guidance and training programs' for citizens (Article $6.2)$.
} 
declarations, they proclaim an abundance of rights without clearly specifying the conditions of their satisfaction. ${ }^{4}$ And second, such treaties and covenants are generally silent about what is to be done - and in particular what third-party or backup responsibilities come into effect - when signatory state parties are either unwilling or unable to abide by their treaty obligations.

What might the costs of such abstraction be? Well, one such cost is sure to come at the level of the practical relevance or meaningfulness of a proclaimed right. It is normal to expect a human right (indeed, any right) to have some discernable practical bearing on our individual and institutional decision-making, even if its bearing is not always decisive against competing practical considerations, including other rights. Some such expectation follows naturally from the idea that rights represent normative standards to which our choices and actions ought to conform. And yet it is clear that the abstractness of a right can undermine its performance in this respect. This is because we need information about the content and allocation of the duties connected to a right if it is going to take up a meaningful place among the array of reasons, values, and practical considerations that bear on our personal and political conduct. Thus, as Henry Shue has argued, a claim of right is in an important sense incomplete until we have spelled out, 'at least a little bit, what it would actually mean for a certain right to be fulfilled and enjoyed. ${ }^{5}$ But these are precisely the sorts of details that abstraction skates over.

Other critics have offered more grandiose assessments of the detrimental effects of abstraction, seeing it as evidence of a commitment to questionable normative and ontological assumptions. ${ }^{6}$ Of late, however, renewed attention has been paid to a longstanding worry about abstract rights that emerges from considerations internal to the theory of rights itself. According to this concern, sometimes referred to as the 'claimability objection' to human rights, ${ }^{7}$ abstract proclamations of rights are not merely incomplete, or entangled with broader philosophical assumptions of questionable validity; they are incoherent. It is this last gloss on the importance of allocating and specifying responsibilities when we talk of rights - particularly as developed by Onora O'Neill - that shall occupy me in this article. ${ }^{8}$

\footnotetext{
${ }^{4}$ Consider, for instance, Article 12 (b), which claims, without adding any further detail, that state parties must take the 'steps necessary for: the improvement of all aspects of environmental and industrial hygiene' (My emphasis).

${ }^{5}$ See Henry Shue, 'Thickening Convergence', The Ethics of Assistance: Morality and the Distant Needy (Cambridge, 1996a), ed. D.K. Chatterjee, pp. 226-227; Henry Shue, Basic Rights: Subsistence, Affluence, and U.S. Foreign Policy (Princeton, 1996b), e.g. p., 157.

${ }^{6}$ For instance, according to some, the inattention of human rights culture towards concrete matters of responsibility signals its lack of appreciation for the significance of 'community,' the 'social dimension' of human life, or the interdependence of human beings [See, e.g. Mary Ann Glendon, Rights Talk: The Impoverishment of Political Discourse (New York, 1991), Ch.4; Amitai Etzioni, The Spirit of Community (New York: Crown Publishers, 1993), pp. 1-23; Shue 1996a, pp. 218-219.]. And according to others, that inattention signals the basis of human rights in a 'Western' system of value, one that prioritizes individual well being over the greater good of the community. [See, e.g. Jack Donnelly, 'Human Rights and Asian Values: A Defense of 'Western' Universalism', The East Asian Challenge for Human Rights (Cambridge, 1999), eds. Joanne R. Bauer \& Daniel A. Bell, pp. 78-79].

${ }^{7}$ See John Tasioulas, 'The Moral Reality of Human Rights', Freedom from Poverty as a Human Rights: Who owes What to the Very Poor? (Oxford, 2008), ed. Thomas Pogge, p. 80, 88-95.

${ }^{8}$ The main sources I shall be referring to are: (a) Onora O'Neill, Towards Justice and Virtue: A Constructive Account of Practical Reasoning (Cambridge, 1996), pp. 128-136; (b) Onora O'Neill, 'The Dark Side of Human Rights', International Affairs, Vol. 81, No. 2 (2005), pp. 427-439.
} 


\section{O'NEILL'S CRITIQUE OF WELFARE RIGHTS}

Those who argue that rights must be claimable tend to start from the widely accepted idea that rights are logically correlated to duties or obligations. ${ }^{9}$ This correlativity is not normally understood to be symmetric. So, for instance, the idea is not that every obligation is the logical corollary of some specifiable right, since the possibility of an imperfect obligation (e.g. of charity or benevolence) that is owed to no one in particular and irrespective of anyone's 'rights' is widely acknowledged to be a coherent one. All that the thesis of logical correlativity entails is that any genuine right be matched to some obligation, or set thereof, on the part of others. In this sense, rights are classified as a kind of claim against others. And on some such grounds, proponents of claimability argue that a right ought to be claimable, a prerequisite of which is that we be able to identify its duty-bearers. In other words, if a right is kind of claim (noun) against others, then we ought to be able to meaningfully and validly claim (verb) it, and this, it is alleged, requires knowing who these others are. This line of reasoning is especially salient in the writings of O'Neill. Consider, for example, the following quotation:

Any right must be matched by some corresponding obligation, which is so assigned to others that right-holders can in principle claim or waive the right (or where not competent to do so, that others be able to at least claim it on their behalf). Unless obligation-bearers are identifiable by right-holders, claims to have rights amount only to rhetoric: nothing can be claimed, waived or enforced if it is indeterminate where the claim should be lodged, for whom it may be waived or on whom it could be enforced. $^{10}$

As described in the previous section, and like other authors who argue for claimability as a necessary feature of rights, ${ }^{11} \mathrm{O}$ 'Neill suggests that talk of unclaimable rights must be understood rhetorically, i.e. as talk that is ultimately about something other than rights. But not all of human rights discourse is at risk of falling into this trap, according to O'Neill; in truth, only talk about a certain class of rights - 'welfare rights,' or rights to goods and services - is at risk of this. According to O'Neill, liberty rights - or rights that demand 'non-interference' - are different from welfare rights in that welfare rights demand a 'specific performance' on the part of obligation holders. ${ }^{12}$ And this performance-demanding feature of welfare rights creates difficulties of coordination and duty allocation that are not present (or at least not present in the same way) in the case of liberty rights. For instance, according to O'Neill, liberty rights - rights to personal security, private property, freedom of association, etc. - can be realized for all providing no one interferes with the behaviour of anyone else. Such negative duties, which in essence involve leaving one another alone, can plausibly be allocated universally, and so we can know by pure moral reasoning alone that the duties correlative to liberty rights are allocated to everyone (or at least to all agents capable of respecting them). Welfare rights, on the other hand

\footnotetext{
${ }^{9}$ This thesis of logical correlativity is most famously attributed to Wesley Hohfeld, who advances it in his discussion of 'claim-rights', which he sees as rights 'in the strictest sense'. See Wesley Hohfeld, Fundamental Legal Conceptions (New Haven, 1923), pp. 36-38. The same idea is also implicit in Joseph Raz's influential account of rights: ' $X$ has a right' if and only if... an aspect of X's well-being (his interest) is a sufficient reason for holding some other person(s) to be under a duty.' Raz, The Morality of Freedom (Oxford, 1986), p. 166.

${ }^{10}$ O’Neill (1996), p. 129.

${ }^{11}$ See Joel Feinberg, Social Philosophy (Englewood Cliffs, 1973), pp. 66-67.

${ }^{12}$ O'Neill (1996), pp. 130, fn. 4.
} 
- rights to healthcare, education, work, an adequate standard of living, etc. - can be realized only through the expenditure of resources, the transfer of goods, and the performance of services. Such positive duties, unlike their negative counterparts, cannot reasonably be allocated to all, and so the question of who bears them is a complicated one. In fact, O'Neill argues, there is not a great deal that we can know about who bears such duties in the abstract, outside the context of a given institutional scheme. ${ }^{13}$ Thus, when conceived of as rights held by all individuals irrespective of institutional affiliation, welfare rights are uniquely unclaimable, or so the argument goes.

Now, the once fashionable notion that liberty rights are characteristically negative and welfare rights characteristically positive, in the very sense described above, has long fallen into disrepute. ${ }^{14}$ Most contemporary moral and political philosophers have come to accept the idea that both kinds of rights, in fact, generate a mixture of positive and negative duties. ${ }^{15}$ This becomes obvious once we consider that welfare rights will typically generate negative duties as well as positive duties: for instance, duties not to interfere with one's means of subsistence, or block one's access to crucial resources. Similarly, liberty rights will typically generate positive duties as well as negative ones: for instance, duties to prevent the infringement of liberty rights through the establishment of a police force and a system of justice. And so this leaves the central distinction of the preceding paragraph in doubt.

O'Neill is, in fact, ready to admit that the distinction between welfare and liberty rights can be muddled in this way. But she nevertheless insists on the basic asymmetry between welfare and liberty rights by drawing on a further distinction between the primary and secondary duties associated with a right. ${ }^{16}$ To illustrate: the protection of liberty rights will indeed require governments to coordinate (e.g. through policing, legislating, judging, prosecuting, jailing, etc.) the complex allocation of secondary duties to enforce citizens' primary duties to avoid infringing upon one another's liberty rights. But this takes for granted that, in the case of such rights, we already know 'who' is bound by such primary duties and 'what' these duties involve: the 'who' includes everyone and the 'what' involves simple non-interference. Governmental agents step in to enforce (however elaborately) a straightforward normative relationship. By contrast, in the case of welfare rights, O'Neill argues, it becomes impossible to claim that institutions similarly enforce a set of known primary obligations. This is because, again, in the case of such performance-demanding rights, there is often little that we can know about their corresponding obligations before these have been organized and allocated under an institutional scheme, e.g. through welfare legislation, a healthcare program, social security provisions, council housing projects, etc. Only once these overarching institutions are in place can we know the shape of the primary obligations - i.e. who owes what to whom - that hold between agents in light of their welfare rights; hence the purported asymmetry with liberty rights. ${ }^{17}$

One uncomfortable consequence of these observations, according to O'Neill, is that we cannot claim, as we commonly do, that welfare rights are both rights and institutionally transcendent moral norms at the same time; one of these claims has to give. For, on the one hand, if we want to hold on to our understanding of welfare rights as rights, then we can only do so in

\footnotetext{
${ }^{13}$ Ibid, pp. 130-132.

${ }^{14}$ Maurice Cranston was the most popular early defender of this view. See Maurice Cranston, What are Human Rights? (London, 1973), pp. 66-67.

${ }^{15}$ See Shue (1996b).

${ }^{16}$ O’Neill (1996), p. 131.

${ }^{17}$ O’Neill (2005), p. 432; O’Neill (1996), pp. 132-136.
} 
the case of welfare rights that have been rendered claimable by an existing institutional scheme. But this undercuts the sense in which such rights are pre-institutional, independently valid, or affirmed (rather than created) by institutions that recognize and implement them. ${ }^{18}$ On the other hand, if this is intolerable, and we opt to preserve our belief in the independent moral validity of welfare rights, then their inherent (pre-institutional) deontic indeterminacy will undermine their status as rights. Instead, we will be forced to identify them in other terms, e.g. as noble aspirations, goals, ideals, imperfect obligations, or 'manifesto rights.' ${ }^{19}$ Our common understanding of welfare rights as moral rights that transcend and, indeed, motivate and justify their own institutional embodiment begins to look unsustainable. ${ }^{20}$

Along with this conceptual upshot of the preceding observations, O'Neill also highlights some of their moral consequences. For instance, she writes:

Proclamations of universal 'rights' to goods or services without attention to the need to justify and establish institutions that identify corresponding obligation-bearers may seem bitter mockery to the poor and needy, for whom these rights matter most. When advocates of Human Rights proclaim universal rights to food or to work or to welfare, yet fail to show who has corresponding obligations, or where claims of right or redress may be lodged, they hurl a weapon that may boomerang. At best a premature rhetoric of rights may have political point and impact. An appeal to the 'manifesto rights' of the sort promulgated in Charters and Declarations invokes and highlights ideals that may guide agitation, politics and legislation in a quest for institutionalized, claimable rights... But at worst a premature rhetoric of rights can inflate expectations while masking a lack of claimable entitlements. ${ }^{21}$

There seem to be two overlapping strands of argument here. According to one strand, the proclamation of unclaimable 'rights' to goods and services is a form of 'bitter mockery to the poor and needy' because it encourages them to believe that they have a realizable or enjoyable claim to relief from (or compensation for) their predicament, when in fact this isn't so - and not because such relief (or compensation) is infeasible but because it simply isn't clear who owes it to them. Remedial action is, in effect, thwarted by ignorance. The mocking or cynical aspect of the proclamation, on such a reading, consists in its attribution of unrealizable entitlements to those who are in desperate need of real help, and certainly not of false hope. ${ }^{22}$

\footnotetext{
${ }^{18}$ O’Neill (2005), pp. 432-433; O’Neill (1996), pp. 133-134.

${ }^{19}$ The term originates in Feinberg (1973), p. 67.

${ }^{20}$ It is unclear whether O'Neill's argument here is based on an epistemological claim (i.e. that we need institutions to help us identify a right's duty-bearers) or an ontological claim (i.e. that only institutions can make the identity of a right's duty-bearers determinate), or both. Ultimately, I don't think anything of serious importance hangs on the matter. If O'Neill is only making the epistemological claim then, it is true, there will be a sense in which welfare rights can exist prior to institutional specification, since such rights may still have ontologically determinate duty-bearers. But this theoretical possibility would be entirely irrelevant in practice, since our inability to actually identify the relevant duty-bearers in such a case would still leave us unable to confirm the right's ontological determinacy, and so unable to justifiably claim its existence. Thus, the basic thrust of O'Neill's objection remains the same on either claim.

${ }^{21}$ O’Neill (1996), p. 133.

${ }^{22}$ It is worth briefly noting here that a right or entitlement can be what I am calling 'unrealizable' for a number of distinct reasons: these include its (a) unenforceability, (b) non-justiciability, or (c) infeasibility. So, for instance, (a) a right may be unrealizable if there are no reliable and available means of enforcing compliance with its attendant obligations. Or, (b) it may be unrealizable because the courts and legislature are unwilling and/or unable to legally administer the right, in which case it is non-justiciable. In other
} 
According to a second strand in O'Neill's argument, however, such proclamations constitute bitter mockery for a different reason. If, at bottom, universal ascriptions of rights to goods and services cannot be coherently regarded as ascriptions of rights, then, according to O'Neill, at best they must be read as affirming the existence and importance of certain moral goals, considerations, ideals, aspirations, or imperfect moral obligations, i.e. obligations owed to others in general, but to no one in particular. ${ }^{23}$ While such norms and requirements can in principle be just as morally important, weighty, or urgent as rights, their importance is nevertheless distinct from that standardly attributed to rights, or to rights-based obligations. This is because rights-based obligations have a direction - i.e. they are owed to some individual or group thereof - and so when they are violated someone or some group of rights-holders is wronged, and so is understandably entitled to remedy or compensation of some form. ${ }^{24} \mathrm{By}$ contrast, when an imperfect duty - owed to no one in particular - is violated, a wrong is committed but no particular person or group has been wronged, and so directed compensation is uncalled for. Thus, according to O'Neill, when unclaimable welfare rights are ascribed universally, the poor and needy are lured into a false sense of entitlement. Such proclamations lead the destitute to believe that the world's brutish indifference towards their misfortune constitutes an injustice done unto them: one that justifies demands for remedial action or (at least) apology and that licenses feelings of resentment and blame. On O'Neill's account, however, the deflating truth is that any injustice done is strictly impersonal, and so the poor and needy are not in fact entitled to make such demands or to legitimately harbour feelings of that sort (nor is anyone entitled to on their behalf). This is another sense - one borne in the falsity rather than the non-realizability of an entitlement - in which O'Neill urges us to see the proclamation of universal welfare rights as a reckless and even cynical act.

\section{NARROW AND WIDE CLAIMABILITY}

So far, I've portrayed O'Neill as understanding the claimability of a right to depend on whether it is possible to identify precisely whom that right can be claimed against. This portrayal requires

circumstances, (c) the duties generated by a right may not be feasible in the present and for the foreseeable future (this is different from their being unenforceable), in which case we might reasonably question the existence of that right (For a useful discussion, see Pablo Gilabert, 'The Feasibility of Basic Socioeconomic Rights: A Conceptual Exploration' in The Philosophical Quarterly, Vol. 59, No. 237 (2009), pp. 651-681) In this strand of O'Neill's argument, (d) a right is deemed unrealizable not because we cannot enforce compliance with its attendant obligations, or because these are unfeasible or nonjusticiable, but because we do not know who bears these obligations. Several authors have run the issues of feasibility and claimability together, most likely because, when a right is infeasible, it is also unclaimable, i.e. it has no identifiable duty-bearers (e.g. see Feinberg (1973), pp. 66-67; Cranston (1973), pp. 68-69; Bernard Williams, In the Beginning was the Deed: Realism and Moralism in Political Argument (Princeton, 2005), ed. Geoffrey Hawthorne, p. 64). But this tendency should be resisted. This is because a right can be unclaimable but nevertheless feasible if, say, we know that it generates feasible duties but cannot yet discern who specifically bears those duties. Precisely because they fudge this distinction, it is not entirely clear whether these authors think claimability (properly understood) is an existence condition of rights.

${ }^{23}$ See Onora O'Neill, Constructions of Reason: Explorations of Kant's Practical Philosophy (Cambridge, 1989), pp. 230-231; O’Neill (1996), pp. 136-153.

${ }^{24}$ See, e.g. Allen Buchanan, 'What's so Special about Rights?', Social Philosophy and Policy, Vol. 2, No. 1 (1984), p. 74; O’Neill (1996), p. 139. 
some qualification. And that is because O'Neill sometimes suggests that the claimability of a right also depends on specifying the content (and not just allocation) of the duties that attach to it. ${ }^{25}$ For instance, in her critique of welfare rights, O'Neill at one point draws attention to the ambiguities of Article 12 of the ICESCR, which proclaims 'the right of everyone to the enjoyment of the highest attainable standard of physical and mental health. ${ }^{, 26}$ As she observes, in proclaiming a right to the highest attainable standard of health, many questions are begged. For one, according to what measure is the index of attainability to be understood? Is this a local standard, in which case the right may turn out (in the context of severely impoverished states) to yield relatively little in the way of claimable healthcare? Or, is the relevant standard of attainability a global one, in which case the right may seem too demanding? Furthermore, on either interpretation, what would such a right require on the ground, e.g. on the part of those (doctors, surgeons, nurses, and physicians) who are in possession of the goods demanded by the right? It is easy to see why O'Neill might categorize these content-related indeterminacies as threats to the claimability of a right. Indeed, how can I meaningfully demand some act or omission from an agent without specifying precisely what it is that I am demanding?

But once we acknowledge this much, it becomes hard to see why O'Neill does not amplify her understanding of claimability even further. This is because there is a rich plurality of information that is plausibly relevant to the claimability of a right. Along with (a) details about the bearers of a right's correlative duties and (b) about the content of those duties, this plurality includes: (c) details about the holders of the right (e.g. how can I validly claim a right that I do not hold?), and (d) details about the weight or priority of the right and its resistance to trade-offs in cases of conflict with other practical considerations, including other rights (e.g. how can I validly claim a right that has been defeated by, say, competing concerns of national security?). ${ }^{27}$ Informational gaps at any of these levels will undermine the support that a right offers claimants who seek to invoke it. Thus, at this point, it's helpful to distinguish between narrow and wide conceptions of the requirements of claimability. According to the narrow conception, which is more or less explicitly adopted by O'Neill, the claimability of a right can be fully secured providing we possess adequately specific information about (a) and (b); according to the wider one, by contrast, the claimability of a right requires specific information of all four kinds - (a), (b), (c), and (d) - and possibly more. What I am now suggesting is that the amplified notion is the more coherent one. If what one wants is to claim the object of some right from others, then indeterminacies of type (c) and (d) will prove just as debilitating as those of type (a) and (b). On the most natural understanding of O'Neill's arguments, then, what claimability actually requires is specific information about a wide range of practical matters.

${ }^{25}$ Indeed, Elizabeth Ashford interprets O'Neill as adopting this broader conception of claimability, which requires identifying 'both the precise content of the corresponding duties and the specific agents responsible for fulfilling them.' Elizabeth Ashford, 'The Duties Imposed by the Human Right to Basic Necessities' in Freedom from Poverty as a Human Rights: Who owes What to the Very Poor? (Oxford, 2008), ed. Thomas Pogge, p. 214 (My emphasis).

${ }^{26}$ See O’Neill (2005), pp. 427-439.

${ }^{27}$ I recognize that, as a Kantian, O'Neill may be unwilling to acknowledge the claim that rights can conflict, and so would also be unwilling to admit that rights have weight. Nevertheless, even the most ardent absolutist about rights - e.g. see Russ Shafer-Landau, 'Specifying Absolute Rights,' in The Arizona Law Review, Vol. 35 (1995), pp. 209-225 - must admit that, until the full content of a right is worked out, there are questions about the lexical priority of rights over one another (and over non-rightsbased considerations) that remain open and important. 
This revision has some important ramifications. Chief among these is the fact that the set of 'unclaimable' rights is likely to expand quite drastically. So long as the claimability of a right was understood to depend exclusively (or at least predominantly) on the identifiability of its duty-bearers, O'Neill was able to point to the allegedly special difficulties involved in allocating the positive duties that attach to welfare rights in order to single out those rights as the sole objects of her critique. ${ }^{28}$ But now that it has become clear that (on pain of arbitrariness) it is wide claimability that is demanded by O'Neill's critique, those objects can no longer be so well isolated. In other words, now that the demands of claimability have been augmented, welfare rights cannot plausibly be the only rights that fall short of those demands. Even if we were to charitably concede to O'Neill her claim that the allocation and (let us also concede, for the sake of argument) content of the duties that correspond to liberty rights are determinate in a way that the duties attached to welfare rights are not, this would still not be enough to contain her critique. Liberty rights are, after all, in no way obviously immune to trade-offs or indeterminacies about their weight or priority. The interminable character of debates about the permissibility of abortion and torture - where conflicts between different rights (e.g. to life or liberty, on the one hand, and to privacy or security, on the other) are a central issue - is a testament to that. And liberty rights are equally beset by indeterminacies regarding who holds them, e.g. do infant, comatose, or psychotic individuals have a right to liberty? The answer is not so clear.

What all this is pointing to is that O'Neill's critique, as expounded above, can be turned not just on welfare rights but on any right for which we lack specific information about (one or more of) details (a), (b), (c), and (d). Understood in this way, O'Neill's critique becomes what is in effect a critique of abstract rights. Abstract rights, as I shall define them, bracket or omit specific details of some kind. ${ }^{29}$ Thus, a right to healthcare is more abstract than a right to, say, a single-payer healthcare system, because it omits reference to any specific form of healthcare. And a right to liberty is more abstract than the related right to freedom from arbitrary arrest, since the latter is a right to freedom from a specific form of coercive interference. Furthermore, a right can be abstract in a variety of respects - i.e. with respect to its holders, duty-bearers, content, and/or weight - and it can be abstract in some respects but specific in others. ${ }^{30}$ Since abstract rights, so defined, are characterized by the very sorts of omissions and indeterminacies that threaten the wide claimability of a right, they constitute the chief object of O'Neill's critique - although this of course does not mean that welfare rights are no longer touched by that critique as well. ${ }^{31}$

${ }^{28}$ I leave aside here some important doubts about the cogency of O'Neill's attempt to single welfare rights out for criticism by way of the distinction between primary and secondary duties. See Tasioulas (2008), pp. 91-92.

${ }^{29}$ This is also how O'Neill herself understands the notion of abstraction: 'Abstraction, taken straightforwardly, is a matter of bracketing, but not of denying, predicates that are true of the matter under discussion.' O'Neill (1996), p. 40.

${ }^{30}$ For a similar definition of abstract rights, see James W. Nickel, Making Sense of Human Rights (Oxford, 2007), $2^{\text {nd }}$ Edition, pp. 23-24. Also see Raz 1986, p. 184; James Griffin, On Human Rights (Oxford, 2008), p. 50; and Waldron (1993), pp. 77-78.

${ }^{31}$ It's worth noting here that the abstractness of a right is something different from its (i) vagueness or (ii) ambiguity, although these are also forms of indeterminacy. A right is vague if it appeals to concepts or predicates that are prone to borderline cases, i.e. cases in which they neither clearly apply nor clearly fail to apply. But not all abstract rights are vague in this sense. Moreover, not all abstract rights are ambiguous in the sense of committing homonymy, i.e. picking out categorically different objects in the way that a right to 'fence' can be both a right to engage in an Olympic sport and to engage in the activity 
All of this brings us back to the initial concern with abstraction. As noted above, references to abstract rights are ubiquitous in human rights discourse. Even specific human rights (e.g. the Burmese people's right to vote) are commonly thought to be derived or applied versions of more abstract counterparts (e.g. the human right to political participation). On the best understanding of O'Neill's critique, however, this widespread reliance on abstraction is a grave error. Since it is part of the very nature of abstract rights to omit fine-grained details about their content, holders, duty-bearers, and priority - details crucial to the claimability of any right - such rights cannot be seen as higher-level rights that exist prior to, or that explain and justify, their more specific counterparts. ${ }^{32}$ At best, references to markedly abstract human rights consist in rhetorical elaborations of what are, at bottom, imperfect obligations or moral goals that can be violated without anyone being wronged in the process. ${ }^{33}$

If we want to avoid this discomforting thought, there are roughly two available strategies. One is to deny that human rights discourse is anything more than superficially abstract and to claim that, underneath this façade, there is a wealth of readily accessible information that can satisfy the stipulated requirements of claimability. This is a strategy that I will briefly explore in the context of human rights law below, in the following section. Another strategy is more aggressive, and denies that the strictures of claimability - wide or narrow - are ones that need to be satisfied at all. This second strategy is, I think, more promising, and one that I shall pursue in Section IV. ${ }^{34}$

\section{SPECIFICATION THROUGH LAW}

One question that I have postponed, up to now, is that of whether the preceding concerns about claimability apply to moral rights or legal rights, or both. Standardly understood, moral rights are rights that exist in light of moral demands and considerations; legal rights, by contrast, are rights that exist under the rules of a given legal system. Defined as such, these two categories of rights

of marking boundaries between properties. See Jeremy Waldron's discussion of vagueness, ambiguity, indeterminacy, and contestability in 'Vagueness in Law and Language: Some Philosophical Issues' in California Law Review, Vol. 82, No. 3 (1994), pp. 509-540.

${ }^{32}$ This is simply a repetition of the criticisms that O'Neill raises against welfare rights, as discussed in Section II, but now applied to abstract rights more generally. Since O'Neill lauds the use of abstraction in moral reasoning elsewhere in her writings [e.g. O'Neill (1996), Ch. 2], one way to interpret my own analysis is as pointing out an inherent tension in her views on abstraction.

${ }^{33}$ I should mention that O'Neill might be willing to accept the existence of abstract rights if they were thought of as merely generalized assemblages of specific and claimable rights (in the way that my right to freedom of movement might be understood as nothing more than a shorthand term for an infinite number of specific and claimable rights, e.g. to stand on my head, to move my arm, to walk outside, etc.). But this is not how abstract rights are normally understood: they are often thought to have independent justificatory force as the grounds of more specific rights, in the way just described. [See also Jeremy Waldron, Liberal Rights: Collected Papers 1981-1991 (Cambridge, 1993 pp. 77-78; Raz (1986), p. 169]. That prominent and important conception of abstract rights - without which we could not affirm a human right to, say, adequate nourishment, since we cannot cite specific and claimable rights to such nourishment that hold in each individual case in advance - would still be unsustainable on O'Neill's account.

${ }^{34}$ In this respect, the current article builds on Tasioulas' response to O'Neill's claimability objection in Tasioulas (2008). That said, my own response (in Section IV) is less dependent on the acceptance of the interest-based theory of rights than his is. 
are clearly distinct and potentially non-overlapping; just think of all the obviously immoral rights that have been upheld by law at some time and place (e.g. rights to hold slaves, to deport Jews, to deny women the vote, etc.). Despite this, there are two good reasons for thinking that O'Neill's critique touches both the domains of morality and law. First, her complaints about claimability and indeterminacy are directed towards human rights culture as a whole, of which human rights law forms an undoubtedly integral part. Indeed, O'Neill herself sometimes draws on legal examples in order to prove her point. ${ }^{35}$ Second, despite their differences, there are important and deep connections between moral and legal rights. It is, in particular, not at all unusual to think of human rights law as giving expression to human rights understood as moral norms. ${ }^{36}$ Since the 1960s and 1970s human rights have, after all, been expressed and articulated largely through the medium of law. And the practical requirements of such rights have been given their most elaborate and detailed formulations in domestic, regional, and international legal systems. This gives scope to the possibility that the specificity and detail with which human rights are handled in the arms of the law can be used to exonerate the whole of human rights culture (in both its moral and legal dimensions) of any blanket charge of abstract indeterminacy. At the very least, that is the possibility that I want to briefly explore here.

As noted in the introduction, international covenants are chock-full of abstract rights (e.g. to food, health, political participation, etc.) that have dramatically unclear practical implications. However, if we look beyond the strict letter of major legal covenants such as the ICESCR and ICCPR (The International Covenant on Civil and Political Rights), at least two relevant modes of legal specification come into view. Perhaps the single most important of these consists in judicial efforts to apply abstract rights to individual cases or judgments, a process which inevitably involves interpretation and which produces a body of case history or precedent that can be referred to in the future. Taken on its own, an individual article in a bill of rights may be normatively opaque, but the explicit wording of that article is only the tip of a much larger legal iceberg, so to speak. With time, the background history of judicial attempts to apply, interpret, and specify the requirements of the article constitutes a vast body of legal and practical information (which includes moral reasoning about individual cases) that lend the article implicit specificity. Of course, the case histories of a given right may not add up to anything very coherent. Previous interpretations of a right may conflict, be mistaken, or suffer from internal contradictions, and (whenever necessary) it is open to judges and legislators to break away from past interpretations of a right. ${ }^{37}$ Nevertheless, case histories do give some practical shape and content to human rights as legally embodied norms.

One of the difficulties of looking to case history as a source of content for human rights is that there is no single legislative and judicial body in charge of drafting, interpreting, and applying such rights. At the international level, one finds the International Criminal Court (ICC) as well as various United Nations Committees tasked with the jobs of interpreting and hearing

\footnotetext{
${ }^{35}$ See the reference in fn. 26 above. There is, furthermore, no principled reason that I can think of for denying that claimability, if it is a necessary feature of rights at all, is a necessary feature of both moral and legal rights (at least so long as we are talking about 'claim-rights' and not some other Hohfeldian category); and so in this very direct sense claimability is as much a legal concern as it is a moral one.

${ }^{36}$ See Gerald L. Neuman, 'Human Rights and Constitutional Rights: Harmony and Dissonance' in Stanford Law Review, Vol. 55, No. 5 (May, 2003), pp. 1868-1869.

${ }^{37}$ For an instructive overview of the complex role of precedent in international law (including international human rights law), see Gilbert Guillaume, 'The Use of Precedent by International Judges and Arbitrators' in Journal of International Dispute Settlement, Vol. 2, No. 1 (2011), pp. 5-23.
} 
individual complaints that fall under the purview of the International Bill of Human Rights (comprised of: the ICCPR, the ICESCR, and the non-binding UDHR). But such international tribunals are designed to complement existing national and regional judicial systems as backups, so to speak. That is, aside from monitoring state behaviour and unilaterally interpreting the content of human rights provisions, such tribunals generally do not hear individual complaints unless national or regional courts are unwilling or unable to do so. Alongside these international schemes, then, one has parallel regional schemes governed by regional conventions, e.g. the European Convention on Human Rights (ECHR), which is binding for all members of the Council of Europe and is interpreted and monitored by the European Court of Human Rights. And human rights frequently have independent presence at the domestic level in the form of constitutional rights.

All of this makes the case history of any particular human right a complicated affair since, in effect, a right may have parallel but disjointed legal formulations and histories. So, for instance, the right to freedom of expression has famously been given a far more demanding interpretation in the First Amendment law of the United States than it has in, say, the ICCPR, where that right has been limited by explicit prohibitions on hate speech. Or, to take another example, the Constitutional Court of South Africa has declined to adopt a UN-Committee's recommended 'minimum core' interpretation of the rights to adequate housing and healthcare proclaimed under the South African constitution, which would require that the court decide on a clear and enforceable (minimum) standard of adequacy. The court instead opted for a progressive interpretation of those rights, reviewing only the 'reasonableness' of the government's steps towards the progressive realization of the rights under the current circumstances. ${ }^{38}$ Under such fragmented circumstances, it makes more sense to talk of plural legal specifications of human rights norms - with no guarantee of convergence or even of efforts towards convergence - rather than a sustained and coordinated legal effort to interpret human rights. Still, even if legal specifications of human rights may vary according to regional and domestic jurisdiction, one can still say that, in any given jurisdiction, a claimant invoking some abstract human right can appeal to (at least) its local case history in order to lend practical determinacy to their claim. And this is of course what's important for addressing O'Neill's critique.

A second way in which the legal culture of human rights contributes to their specificity is through the drafting and signing of special conventions, e.g. on the rights of the child, the rights of persons with disabilities, against racial or gender discrimination, etc. These subject-specific treaties provide crucial supplements to the main instruments of human rights law. They do this firstly by addressing special issues that core human rights have left unaddressed. This sort of supplementation is most evident in the case of the Convention on the Rights of Disabled Persons, for instance, which establishes a set of rights that address the specific needs and circumstances of disabled persons, something that the core instruments make no attempt to do. Secondly, a special convention may explore a topic that is only superficially addressed by the core conventions and declarations. So, for instance, the ICCPR proclaims a human right not to 'be subjected to torture or to cruel, inhuman or degrading treatment or punishment.' But definitions of torture, cruelty, inhumanity, and degradation are lacking here. And so are clear guidelines regarding the steps to be taken in order to enforce and promote such a right. The United Nations Convention Against Torture explicitly addresses both outstanding issues in far greater detail.

At the very least, this brief legal excursus should make us hesitate before imputing the modern practice of human rights with any general disregard for detailed questions of content,

\footnotetext{
${ }^{38}$ See Neuman (2003), p. 1878.
} 
priority, and obligation. It's clear that the formidably diverse international network of human rights law is at the vanguard of efforts to make human rights meaningful, determinate, claimable, and ultimately enforceable norms.

This raises an additional point about the complementarity of philosophical and legal efforts to articulate and understand human rights. Philosophers often approach human rights law with a condescension buttressed by a logical distinction between what has been or is legally recognized as a human right and what ought to be recognized as such. ${ }^{39}$ It is important that we draw such a distinction, and it is healthy to aspire towards conceptual rigour, unity, and coherence in our proclamations of human rights. But philosophers ought to guard against the excessive condescension that these distinctions and aspirations can naturally arouse. One reason for this is that, despite occasional squabbles with the content of the law, in practice philosophers tend to work up their theories of human rights in close consultation with that content. ${ }^{40}$ Another is that there is little reason to think that the forms of practical reasoning employed by the legal authors of human rights are very different from those employed under more philosophically rigorous auspices. This is especially true given that the lawyers, scholars, judges, activists, and politicians behind the design and implementation of human rights law naturally tend to see themselves as giving legal expression to norms that have independent moral validity. ${ }^{41}$ Given all this, it is unreasonable to view the authors, practitioners, and interpreters of human rights law as engaged in a task hopelessly detached from philosophy. Rather, it seems more accurate to see them as taking on the lion's share of the moral-practical-philosophical burden: giving abstract but practicable expression to human rights in conditions of modernity, specifying them where necessary, and applying them to individual cases in ways that philosophical theory (later) plumbs for inspiration. ${ }^{42}$

Although these observations do help to absolve human rights culture of any blanket charge of cynical, naïve, or lazy abstraction, they can also play into O'Neill's hands. This is because the legal specification of human rights, at least on one understanding, is a matter of institutionalization. That is, positivization through law can be understood as a way of specifying various aspects of a right in accordance with an extant institutional scheme. Or, we might understand the legal expression of human rights as part of the creation of an institutional scheme (e.g. a treaty system, a healthcare system) that itself gives determinate and claimable shape to human rights. Human rights law may sometimes be institutional in the first sense and sometimes in the second, depending on the case. Yet all of this is entirely compatible with O'Neill's thesis

${ }^{39}$ See, e.g. James Griffin, 'Discrepancies Between the Best Philosophical Account of Human Rights and the International Law of Human Rights' in Proceedings of the Aristotelian Society, Vol. 101, No. 1 (2001), pp. 1-28.

${ }^{40}$ See e.g. Griffin's 'bottom-up' approach to human rights (Griffin 2008, pp. 29-30) Tasioulas' concern with 'fidelity' to the post-1948 culture of human rights (John Tasioulas, 'Are Human Rights Essentially Triggers for Intervention?' in Philosophy Compass, Vol. 4, No. 6 (2009), pp. 938-950), and Joseph Raz and Charles Beitz's explicit theoretical focus on the modern political 'practice' of human rights [e.g. Joseph Raz, 'Human Rights without Foundations' in The Philosophy of International Law (Oxford, 2010), eds. J. Tasioulas \& S. Besson, esp. pp. 323-324, 334-337; Charles Beitz, The Idea of Human Rights (Oxford, 2009), pp. 7-13].

${ }^{41}$ See Neuman (2003), pp. 1868-1869.

${ }^{42}$ Note I am not here suggesting that human rights are norms that are necessarily destined for embodiment in law. For a version of this kind of claim, see Jürgen Habermas, 'The Concept of Human Dignity and the Realistic Utopia of Human Rights' in Metaphilosophy, Vol. 41, No. 4 (2009), pp. 469470. 
that, before legal or institutional specification takes place, some (or perhaps very many) human rights will remain abstract to the point of non-claimability and thus non-existence. This only bolsters her claim that the law does not affirm such rights, but rather creates rights where none previously existed. As a form of institutionalization, the legal specification of human rights does not of itself guarantee their independent, moral specificity. In order to adequately address O'Neill's concerns, then, we need to grapple directly with the question of whether claimability is a necessary feature of rights at all.

\section{MUST RIGHTS BE CLAIMABLE?}

Among the most elemental aspects of a right has to be its nature as a valid claim or entitlement against others. That is what's implied by the thesis of logical correlativity after all. And it's not adding much to say that any such claim (noun) should also be one that can be meaningfully and justifiably claimed (verb) against its addressees. ${ }^{43}$ But there are different ways of interpreting the strength of this naturally consecutive thought, and we ought to carefully consider which one we mean to adopt. On one plausible interpretation, what we mean is the very thesis that we have been considering up to now: that claimability - and thus, the specificity of a right's holder(s), duty-bearer(s), content, and priority - is a conceptually necessary feature of rights. However, on another, equally eligible interpretation, what we mean is simply that claimability is an important and valuable feature of rights, but not a necessary one. Both of these interpretations present us with ways of building on the central motivating observation of O'Neill's critique: that a right consists in a valid claim against certain agents, and that its holders (or some third party) should be able to claim it against them. But the availability of the second interpretation is significant because it allows us to remain true to that observation without also saddling us with an unnaturally demanding conception of rights.

Ordinarily understood, the existence or validity of a claim can be established in the absence of specific information about its addressees and content. For instance, consider how naturally we recognize the claim of a newborn infant to basic nourishing care and support; and this, without any specific information about who ought to deliver such care (e.g. are the parents of the child available and competent, or will these obligations fall on others?) and what concretely ought to be done. Such claims seem worthy of recognition on account of roughly three factors: (a) the existence of a sufficiently important need, status, interest, or vulnerability; (b) the feasibility of its satisfaction by the action and/or omission of some competent and available agent(s); and (c) the reasonableness of demanding the required action and/or omission from the agent(s) in question. ${ }^{44}$ Since these factors can be established even if all we know about (b) and (c) is that some worldly agent(s) is/are capable of fulfilling the relevant need or interest by some reasonable means, the question then becomes why we ought to abandon these intuitive criteria in favour of O'Neill's more stringent set. The answer is, upon reflection, not at all clear, especially when we consider that the difficulty of giving detailed or specific shape to a claim is usually an indication that there is simply more than one reasonable and effective way to fulfill it. $^{45}$ Moreover, given that parallel forms of indeterminacy are expected and philosophically

\footnotetext{
${ }^{43}$ See Feinberg (1973), pp. 64-67.

${ }^{44}$ Shue (1996b), e.g. p. 165 rightly emphasizes the importance of this third set of considerations in establishing the validity of any right or claim.

${ }^{45}$ Tasioulas (2008), p. 94. Also see Neil MacCormick, Legal Right and Social Democracy: Essays in Legal and Political Philosophy (Oxford, 1982), pp. 161-164, for a similar line of reasoning.
} 
tolerated in other areas of moral and legal reasoning - e.g. about the moral virtues, about the allthings-considered 'right thing to do', about the meaning of legislative statutes, etc. ${ }^{46}$ - we might ask why we shouldn't also expect and tolerate indeterminacy when we reason about claims or rights.

The fact that O’Neill does not offer us any salient philosophical guidance at this critical juncture, beyond that of simply pointing us back to the original observation that rights are a kind of claim against others, is a serious weakness of her account, especially since her uncompromising endorsement of claimability imposes disturbing limits on the ascription of rights. Consider, for example, the case of the Murle of South Sudan, a people starved by drought and who live under a deeply fragile state. Since domestic remedies are (let us assume) unavailable, it is hard to say precisely who owes such people food relief. Nevertheless, given the patent feasibility of remedial action as well as the eminent reasonableness of holding at least some existing agent(s) bound to undertake it, it seems clear that help is rightfully owed to the Murle and that they would be wronged if such help were not somehow provided to them (we can even provide a rough account of who these agents are: affluent individuals and nations for whom providing life-sustaining aid would require comparatively minimal sacrifice, relief-oriented NGO's, international aid agencies, etc.). ${ }^{47}$ But these simple and intuitive conclusions are not available to us on O'Neill's account. On her view, a failure to provide aid to the Murle may constitute an injustice of some sort, perhaps even a deeply grave one, but not an injustice done unto them, i.e. one that can justify demands for further remedial action and that licenses special feelings of resentment and blame on their part. This ought to weigh heavily on us when we consider the merits of O'Neill's uncompromising position on the importance of claimability in rights claims. Particularly so in light of the fact there are, as mentioned, other ways of acknowledging claimability's importance that do not have an equally counter-intuitive effect.

It is plainly open to O'Neill (and others) to straightforwardly deny the intuitive character of, say, the Murle's right to aid or a newborn child's right to nourishing care and support (at least in cases where confusion may exist about the identity of the relevant caretaker, and/or some other detail). Or she may reject the need to theoretically accommodate such intuitions in the first place, opting instead to correct, wherever necessary, our judgments about such matters. Given the already-noted lack of a deeper theoretical argument in favour of her strict position on claimability, however, the second strategy of reply isn't going to work; in the absence of such an argument, most (if not all) of what we have to work with to decide the issue at hand are our intuitions themselves. This leaves O'Neill with the first strategy. But if that is her method of reply, then it is fully open to each of us to consult our own intuitions and decide the matter accordingly. My suspicion is that most will not find themselves at ease in, for example, denying the Murle a valid claim or right to aid, and so the prospect of acknowledging the importance of claimability in a way that does not force them to do so will hold greater theoretical allure.

What, then, would it mean to adopt the less stringent understanding of the importance of claimability that was outlined at the beginning of this section? At the very least, it would involve acknowledging the preferability of knowing just what demands are generated by a right as well as just who is bound by them, among other relevant details. As emphasized in the introduction,

\footnotetext{
${ }^{46}$ Consider, for example, the widespread enthusiasm that has greeted Rawls' notion of the 'burdens of judgment,' according to which 'all our concepts... are vague and subject to hard cases.' John Rawls, Political Liberalism (New York, 1996), p. 56.

${ }^{47}$ Shue's discussion of how to allocate duties of assistance is highly instructive in this regard. See Shue (1996b), Ch. 5.
} 
our understanding of a right is always imperfect and incomplete, and its meaning and practical relevance always diminished, until we possess a thorough comprehension of its content, weight or priority, holders, and duty-bearers, and of how these elements can change depending on the circumstances of application. This sort of comprehension is never there from the start, however. It is a product of continuous work and effort, much of which is taken on, as I stressed above in Section III, by legal and political institutions. ${ }^{48}$ Given the obvious importance of such work, moreover, it seems reasonable to affirm not just its value but also its obligatory nature. That is, on the sort of view we are contemplating here, abstract human rights can reasonably be seen as imposing widespread duties to help establish institutions that will undertake the arduous work of specifying, applying, and rendering them claimable. ${ }^{49}$ That the second interpretation allows us to affirm all of this without also forcing us to adopt an unnaturally demanding conception of rights is what accounts for its special dialectical appeal. ${ }^{50}$

With this plausible interpretation of the value of claimability in hand, the concerns raised by O'Neill's critique can be allayed. ${ }^{51}$ Not only can we make good philosophical sense of abstract rights that transcend and, indeed, motivate their own institutional implementation, we can also absolve human rights culture of any charge of naïveté, mockery, or cynicism that is premised on its heavy deployment of such rights. Moreover, lingering concerns about the realizability (if not falsity) of abstract rights can at least be contained by the plausible thought, noted above, that such rights impose widespread duties to help establish institutions that will perform the crucial work of determining their specific requirements. Now that all this has been established, I want to conclude by filling in the story from the other side, so to speak. That is, by illustrating some of the crucial functions of abstraction in rights discourse below, I hope to show that abstract rights are not only theoretically coherent but also useful and important.

\section{THE USES OF ABSTRACTION}

Human rights instruments may be replete with references to abstract rights that leave a host of important practical questions unanswered, but there are some ready explanations for these informational gaps. One is that the drafters of international declarations like the UDHR are under special pressure to produce documents that will be accessible to a wide audience that includes laypersons from a variety of cultural, linguistic, and national backgrounds. This means that a

${ }^{48}$ This isn't to say that institutions are the sole means of specifying rights. For instance, Shue (1996b, pp. 111-131) is able to say many plausible things about what the affluent owe to the global poor without referring to any given institutional framework.

${ }^{49}$ See Ashford (2008), p. 215 \& Pablo Gilabert, 'Humanist and Political Perspectives on Human Rights' in Political Theory, Vol. 39, No. 4 (2011), p. 457, who make a similar point.

${ }_{50}$ There is a third interpretation that, I should mention, also has this virtue. According to it, claimability is indeed a necessary feature of rights. However, it can be achieved with as little as a rough idea of a right's holder(s), duty-bearer(s), content, and priority. This corresponds, broadly, to the (weaker) sort of claimability requirement that we find endorsed by Nickel (2006), pp. 30-32, Griffin (2008), pp. 107-110, and Ashford (2008), pp. 215-217. But since it's unclear whether there is anything of real significance riding on the preservation of the term 'claimability' here, it's unclear how it differs from my own position, which is similarly tolerant of indeterminacy. I shall therefore leave this possibility aside.

${ }^{51}$ The fact that the preceding observations are independently reinforced by the interest theory of rights - according to which the existence of a right can be known before one has answered the question of exactly which agents are bound by it and what is required of them [See Raz (1986), pp. 184-185; Tasioulas (2008), pp. 92-93] - speaks in favour of both. 
premium is placed on brevity and simplicity, rather than exhaustive treatment in the form of a huge multiplication of norms. ${ }^{52}$ Another important factor is the nature of human rights declarations, covenants, and treaties as objects of international agreement. Since it is typically international committees that draft the human rights declarations and treaties adopted by global governance institutions such as the United Nations (UN), the content of such documents is inevitably constrained by the limits of what those committees are able to agree upon. And, of course, such constraints are especially intense when a drafting committee is made up of religiously, culturally, and politically diverse delegates, as is often the case. For instance, during the drafting of the UDHR, the Soviet delegation proposed an alternative formulation of Article 22 that was more explicit about the material and legislative duties of states with respect to the socio-economic rights of their citizens. But the Soviet formulation was shot down by a number of delegations (including that of the United States) that were ideologically uncomfortable with the idea of taking on clear and demanding obligations vis-à-vis socio-economic rights. ${ }^{53}$ The result is that we are now left with an Article 22 that is more opaque about state responsibilities than it might have been. And one can easily imagine how similar disagreements likely lead to the watering down of other proposed articles.

A third factor favouring this sort of reticence stems from the intended universal scope of the human rights proclaimed in international declarations, treaties, and covenants. This is because the pressure to formulate a right in abstract or non-specific terms mounts in proportion to the range of contexts and cases it is intended to cover. If we look carefully at the human rights articulated even in a document as celebrated as the Universal Declaration, it quickly becomes apparent that many of its proclaimed rights are too specific to be universal. For instance, the right to work and to join trade unions clearly presuppose a modern market-based economy. ${ }^{54}$ This makes such rights inappropriate in the context of, say, remote hunter-gatherer societies (rare as these may be) that don't participate in any such economic system. The right to 'periodic and genuine elections ${ }^{, 55}$ is equally likely to be inappropriate in some contexts. Without any detailed knowledge of how such societies function politically, for instance, the members of tribes buried deep in the Amazon jungle cannot necessarily be said to have a right to vote. ${ }^{56}$ Nor is it plausible to assign all persons a right to the institution of marriage understood as a union between spouses, i.e. 'husbands' and 'wives. ${ }^{57}$ Among other peoples, the Mosuo of China famously do not practice marriage in any such conventional sense, favouring instead a custom of informal sexual visitations across matrilineal households. ${ }^{58}$

${ }^{52}$ See Johannes Morsink, The Universal Declaration of Human Rights: Origins, Drafting, and Intent (Philadelphia, 2001), pp. 33-35. There are of course other reasons, like efficiency, for favoring generality and succinctness in the law. For instance, Jeremy Bentham famously complained of the senseless 'multitude' of laws prohibiting the stealing of vegetables in Georgian England, where instead of having generic statutes, one had 'one law for one sort of vegetable, another for another.' See 'Letter V' in The Collected Works of Jeremy Bentham: On the Liberty of the Press, and Public Discussion, and other Legal and Political Writings for Spain and Portugal (Oxford, 2012), eds. Catherine Pease-Watkin and Philip Schofield, p. 183.

${ }^{53}$ See Morsink (2001), pp. 228-230.

${ }^{54}$ Article 23, UDHR.

${ }_{55}^{55}$ Article 21, UDHR.

${ }^{56}$ This is, of course, providing we see such peoples as truly isolated and not, say, as citizens of Brazil.

${ }^{57}$ Article 16, UDHR.

${ }^{58}$ One question that is raised by these examples is that of what we are to make of these purported human rights, if they are not in fact universal. Human rights are, after all, supposed to be rights possessed 
Of course, the mere fact that some prescribed practice (e.g. elections, a market-based economy, etc.) has not taken hold in a given community is not in itself a reason to deny that it ought to. The ostensible non-universality of the rights described above seems to be due to at least two possible factors: (a) their fulfillment is drastically infeasible in the specified context; and (b) the values, interests, or considerations (e.g. in reproduction, intimacy, kinship, social standing, etc.) served by such rights seem adequately servable by other less conventional means that have already taken root in that context. Either way, the result is that a right can only attain full universality if it is formulated in such a way as to remain silent with respect to concrete questions of societal circumstance, deontic prescription, and institutional implementation, e.g. questions about what form of marriage one is entitled to, what type of economy one participates in, what kind of say one should have in one's government, etc. As a way of not pronouncing on such matters, then, abstraction is vital to the universal reach of rights. It allows us to avoid saddling rights with content that would render them inappropriate in certain contexts, objectionably partisan, and that would anchor them in a particular moral and institutional culture. And it also allows us to formulate rights in an open-ended manner that enables their practical content and implications to vary dynamically from context to context. ${ }^{59}$ All of this is surely important to addressing concerns about the ethnocentrism or 'Western' bias of human rights.

Still, a reliance on abstraction also presents challenges of its own. Because it is a way of, essentially, not commenting on the nitty-gritty practical implications of a right, it leaves us with a great deal to sort out when the time comes to actually apply an abstract right to some specific case or range thereof. For any such application, an innumerable array of normative and empirical factors will have to be taken into account. And this raises the question of who can authoritatively undertake such work. ${ }^{60}$ In particular, I want to focus here on the political and legal side of this question, i.e. which institutions are best placed to determine the specific requirements of abstract human rights? I've already said a good deal (in Section IV) about the centrality of legal efforts to specify human rights, but this still leaves important jurisdictional questions wide open. So, for instance, should the authority to interpret abstract human rights rest in all cases with international legal institutions, or should regional and domestic legal institutions be able to decide for themselves how to implement and interpret such rights within their local jurisdiction?

In deciding this question a number of epistemic considerations naturally come into view. In order to competently interpret the locally applicable content of a human right (e.g. the human right to adequate food), an interpreter must at least have (a) a basic grasp of the interests (or

by all human beings, irrespective of nation, race, creed, tribe, or culture. One plausible solution is to accept the possibility of two varieties of human rights. On the one hand, there are abstract and consummately universal human rights: rights that apply to all individuals in all cases, even though their deontic implications are protean and may vary (e.g. the human right to political participation). And, on the other hand, there are derivative or specific human rights: rights that are generated by the application of a universal human right to a specific (cultural and/or institutional) context, taking into account the special features of that context, but that are not themselves universal in scope (e.g. the human right to periodic and genuine elections). According to this sort of picture, many of the rights posited by international and domestic law are indeed human rights, although they are so in light of being broadly applicable specifications of universal rights, not in virtue of being universal human rights themselves. For a similar view, see Gilabert (2011), p. 445; Griffin (2008), Sec. 2.8.

${ }^{59}$ This is what Raz and Tasioulas refer to as the 'dynamicity of rights'. See Tasioulas (2008), pp. 9298, esp. p. 94; Raz (1986), pp. 185-186.

${ }^{60}$ See Diane F. Orentlicher, 'Relativism and Religion' in Human Rights as Politics and Idolatry (Princeton, 2001), p. 144; Joseph Raz, 'Human Rights in the New World Order' (DRAFT), Sec. 3. 
other normative considerations) that ground the right, (b) a good sense of their moral weight or priority, and (c) a solid understanding of the relevant facts on the ground, e.g. facts about who is systematically deprived of the good protected by the right (and why), what local resources can be allocated towards its realization (and under what constraints), who can be fairly and feasibly saddled with duties to distribute those resources, and what social traditions, practices, and institutions are locally in play. If regional and domestic legal institutions are both responsible and cognitively competent (and I grant that this is a big if), primary interpretative authority would seem best placed in their hands, since local agents are likely to know the most about - as well as show the most sensitivity towards - (c) the relevant facts on the ground. ${ }^{61}$ The fact that, for obvious reasons, granting such interpretive license to adequate domestic institutions comports well with the ideal of national self-determination can only serve to reinforce this conclusion.

And so the parallel but disjointed (i.e. national, regional, and international) legal specification of human rights, which we earlier lamented for its daunting complexity, now looks more like something to be celebrated on both moral and epistemic grounds. Moreover, that abstract rights are, in their dynamic open-endedness, uniquely suited to serve as the focal points of such an interpretive division of labour is one of their central advantages. This, then, constitutes a fourth function of abstraction: its facilitation of a delegative system of human rights interpretation, one that embraces something like the European Union's legal notion of a 'margin of appreciation,' according to which member states can be granted some interpretive leeway in their definition and implementation of human rights. This also completes the optimistic picture of abstract rights that I have been trying to defend in general. Not only are abstract rights philosophically coherent, they render the language of rights manageable, conciliatory, and serve as a conduit for its universalist aspirations. Last but not least, abstraction can help disarm worries about the culturally insensitive character of human rights, since it holds open the possibility that a single set of human rights (like the UDHR) can be implemented in contextually diverse ways and its local implications fleshed out by those best placed to understand them: often, local agents themselves. $^{62}$

aetinson@gc.cuny.edu

${ }^{61}$ This parallels the justification for the allowance of a 'margin of appreciation' by the European Court of Human Rights in national interpretations of the ECHR among EU members. See Neuman (2003), pp. 1881-1886; Also Burleigh Wilkins, 'International Human Rights and National Discretion' in The Journal of Ethics, No. 6 (2002), pp. 373-382.

${ }^{62}$ In writing this article, I benefited greatly from the constructive feedback of Elizabeth Ashford, Kimberley Brownlee, Roger Crisp, Pablo Gilabert, Peter Jones, Joshua Keton, James W. Nickel, Onora O’Neill, Adina Preda, Mauro Rossi, Jeremy Waldron, Daniel Weinstock, two anonymous reviewers at Utilitas, and editor Brad Hooker. 